\title{
Taguchi approach with Multiple Performance Characteristics for improving Productivity and Quality of Steel in single stand Cold rolling mill
}

\author{
Vivek Anil Vaidya \\ Research Scholar,BapuraoDeshmukh College of Engineering, Wardha. Nagpur, India
}

\begin{abstract}
Taguchi method is generally used in optimizing process parameters of single response problem. But optimizing of a single response results in the non-optimum values for remaining. So, multi characteristics response optimization may be the solution to optimize multi response simultaneously. This paper presents application of Taguchi optimization method for simultaneous minimization of thickness variation and improving flatness of cold rolled strip.The approach of Taguchi Design for multi objective optimization problem based on multi characteristics response optimization model and utility concept which is used to optimize of process parametersin cold rolling of steel. Taguchi approach which involves using orthogonal arrays to organize parameters affecting the process and the levels at which they should be varies. Taguchi's L9 orthogonal array is selected for experimental planning. Taguchi based design of experiment applied in second pass in single stand reversing cold rolling mill to optimize rolling parameters for improving thickness variation and flatness of the steel strip. The experimental results showed that combination of process parameters is essential to achieve simultaneous minimization of thickness variation and flatness improvement.
\end{abstract}

Keywords: Optimization, Cold rolling, uncoiler,Taguchi method, orthogonal array \&Signal to noise ratio.

\section{Introduction}

Rolling is the process of plastically deforming metal by passing it between hot or cold rolls. It is most widely used forming process, which provide high production and close control of final product[1][2]. The metal is subjected to high compressive stresses as a result of friction between the rolls and metal surface. Rolling processes can be mainly divided into hot rolling and cold rolling. The initial breakdowns of ingots into blooms and billets is done by hot rolling this is followed by further hot rolling into plate, sheet, rod, bar, pipe, rail. The purpose of a cold rolling mill is to successively reduce the thickness of the metal strip and/or impart the desired mechanical and micro structural properties. The cold rolling of metals provides flat product such as sheet, stripand foil with good surface finishes and increase mechanical strength with close control of product dimensions. Tandem type rolling mills used for larger scale production, whereby the strip undergoes a single pass through a train of rolling stands before being wound into coil form. The single stand type rolling mills are usually operated as "reversing" mills, whereby the strip is successively wound and unwound in coil form as it is repeatedly passed back and forth through the single mill stand. Reversing mills are generally used for smaller scale production of the cold rolled products.Cold Rolling mill stand consists of work rolls, back up rolls, bearings, housing for containing these parts and a drive for applying power to the rolls and controlling the speed. Fig 1 shows schematic representation of single stand 4HI Cold rolling mill configuration consists of two work rolls and two back up rolls. The back up rolls provides rigid support to prevent work roll bending \& flexure.There are two hydraulic Jacks mounted on top of the housing on either side which provide rolling force of back roll housing and adjust roll gap. The strip coil fed to mill via tension reel on either side of mill stand.As the strip exists the mill stand it wound tight on tension reel on other side which is and expanding mandrel that maintain contant tension during rolling process while reel on entry side maintain back tension during rolling.

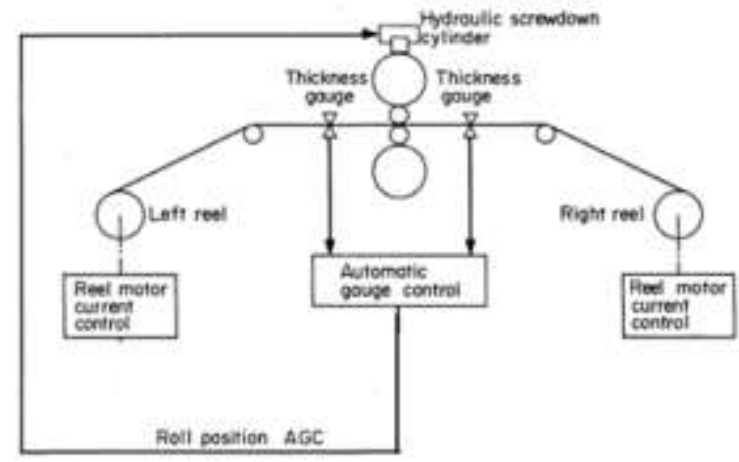

Fig. No.1Schematic representation of Single stand $4 \mathrm{HI}$ reversing cold rolling mill 
At heart of the rolling process is the deformation of strip in roll bite. One of the most important component in the deformation due to rolling force which has dominating effect on the accuracy of thickness and flatness of the rolled strip. Principal parameter affecting resistance to deformation are work hardening and friction at roll bite. Generally roll force can be represented as function of work roll diameter, strip width, material chemical composition, metallurgical characteristics, friction, work hardening, strain, strain rate, reduction, entry and exit tension (Bland \& Ford , 1948 and 1951)[7]. In practice rolling force is measured using load cells. Since rolled metal strip is used in many applications requiring strict adherence to tolerances, such as in theaerospace, automotive, construction, container, and appliance industries, it necessary to optimized rolling parameter in order to obtain productivity and quality metals. Various Process models for cold rolling mills have been intensively developed in the last years, hoping to increase quality of steel strip and productivity of rolling processes. The availability of robust \& accurate models is associated for optimization has been intensely explored in the literature.Application of Taguchi based Method in single stand cold rolling mill for optimization of cold rolling process parameters is single objective optimization problem. The single objective optimization method cannot achieve satisfied solutions. Rolling parameters optimization to achieve simultaneous characteristics like thickness variation and flatness improvement is a typical multi-objective optimization problem. It is one of the key factors for quantity and quality of the production.

Taguchi method is a statistical method developed by Taguchi and Konishi [8]. Initially it was developed for improving the quality of goods manufactured (manufacturing process development), later its application wasexpanded to many other fields in Engineering.Taguchi methods to quality control have been used to optimize the process parameters of engineering experiments [9]. The Taguchi approach has successfully applied in several industrial applications.This approach has been unique and powerful quality improvement discipline that differs from traditional practices. However, original Taguchi techniques was designed to optimize a single performance characteristics and the same was employed in the past for optimization in different process. Several modification were suggested to the original Taguchi method for multi response optimization such as Principal Component Analysis (PCA), Data Envelopement Analysis (DEA) and Grey Relational Analysis (GRA). However all these modification increase computational process complexity and require proper engineering judgement [6].

This paper introduces a simple modification to taguchi method for multi objective rolling process optimization. In the $1^{\text {st }}$ stage taguchi method used to determine optimum process parameters for multi objective optimization for single stand cold rolling mill. In the second stage based on utility concept, establishes optimum values for combination of process parameters of multiple performance.A customer evaluates a product based on a diverse quality characteristics. These evaluations on the different characteristics should be combined to drive a composite index that will result in a rational choice. This composite index represents the utility of a product. The overall utility of product indicates its usefulness to the evaluators the utility of a product on a particular characteristics indicates the usefulness of the product characteristics. The sum of the utilities of each quality attributes represents the overall utility of a product. It is difficult to obtain the best combination of process parameters, when there are multi-response to be optimized.The adoption of weights in the utility concept helps in this difficult situations by differentiating the relative importance of various responses. If xi represents measure of effectiveness of the ith process response, the overall utility function can be written as:

$$
\mathrm{U}\left(\mathrm{x}_{1}, \mathrm{x}_{2}, \ldots . \mathrm{x}_{\mathrm{n}}\right)=f\left[\mathrm{U}_{1}\left(\mathrm{x}_{1}\right), \mathrm{U}_{2}\left(\mathrm{x}_{2}\right) \ldots \ldots . . . \mathrm{U}_{\mathrm{n}}\left(\mathrm{x}_{\mathrm{n}}\right)\right]
$$

Where $U(x 1, x 2 \ldots x n)$ is the overall utility of $\mathrm{n}$ process response characteristics and $U i(x i)$ is utility of $i$ th response characteristic. Assignment of weights is based on the requirements and priorities among the various responses. Therefore the general form or weighted from of Eq.(1) can be expressed as

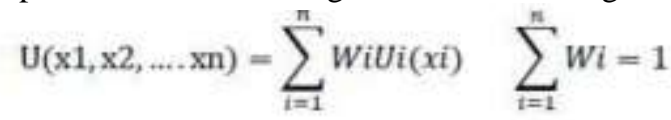

Where $\mathrm{Wi}$ is the weights assigned to the ith response characteristics.

Following are the output parameters affecting product quality and productivity of cold rolling process.

1. Output strip thickness variation.

2. Flatness \& shape of output strip.

3. Power consumption.

4. Production rate.

Following are the input parameters

1. Entry tension.

2. Exit tension.

3. Percent \% Reduction in each pass.

4. Rolling speed.

5. Coolant \% (Coefficient of friction).

6. Work roll Bending pressure. 
Objective function can be

1. Minimize Output strip thickness variation.

2. Improve flatness \& shape of output strip.

3. Minimize power consumption.

4. Maximize production rate.

In the present study we have taken strip thickness variations and strip flatness quality characteristics are considered as a responses for the optimization of process parameters of single stand cold rolling mill.

\section{Methodology}

Rolling Parameter generation or pass schedule is an important aspect in the operation of Single stand reversing cold rolling mills. Table nol shows the material data for input material and output desired, depend on input and output data a roll pass schedule prepared. The basic procedure for the scheduling of cold rolling mills is usually based on past experience, on trials or on rules of thumb [14][3]. Table no.2 shows the typical pass schedule. Our experiment is focused on optimization of control factors for $2^{\text {nd }}$ pass only. The objective of the experiment is to minimize thickness variation or maximize \% of strip length under specified tolerance limit of target thickness and flatness improvement by optimizing rolling control parameters.

\begin{tabular}{|l|l|l|l|l|l|l|}
\hline $\begin{array}{l}\text { Input } \\
\text { thickness }\end{array}$ & $\begin{array}{l}\text { Output } \\
\text { thickness }\end{array}$ & $\begin{array}{l}\text { Total } \\
\text { Reduction }\end{array}$ & No of pass & $\begin{array}{l}\text { Material } \\
\text { Grade }\end{array}$ & Width & $\begin{array}{l}\text { Wt of the } \\
\text { coil }\end{array}$ \\
\hline $2.15 \mathrm{~mm}$ & $0.38 \mathrm{~mm}$ & $82.32 \%$ & 8 & ST29DC & $1200 \mathrm{~mm}$ & 20 Ton \\
\hline
\end{tabular}

Table no. 1 Material data

\begin{tabular}{|c|c|c|c|l|l|l|l|}
\hline Pass No. & Entry thk & Exit thk & Reduction & $\begin{array}{l}\text { Exit } \\
\text { tension }\end{array}$ & $\begin{array}{l}\text { Entry } \\
\text { tension }\end{array}$ & $\begin{array}{l}\text { Rolling } \\
\text { speed }\end{array}$ & $\begin{array}{l}\text { Roll } \\
\text { bending Pr. }\end{array}$ \\
\cline { 2 - 8 } & $\mathrm{mm}$ & $\mathrm{mm}$ & $\%$ & $\mathrm{Kg}$ & $\mathrm{Kg}$ & $\mathrm{mpm}$ & bar \\
\hline 1 & 2.15 & 1.735 & 19.302 & 12200 & 2000 & 300 & 80 \\
\hline 2 & 1.735 & 1.4 & 19.302 & 12200 & 7200 & 500 & 80 \\
\hline 3 & 1.4 & 1.13 & 19.302 & 12200 & 7200 & 600 & 80 \\
\hline 4 & 1.13 & 0.912 & 19.302 & 12200 & 7200 & 600 & 80 \\
\hline 5 & 0.912 & 0.736 & 19.302 & 10682 & 7121 & 600 & 80 \\
\hline 6 & 0.736 & 0.594 & 19.302 & 8600 & 5734 & 600 & 80 \\
\hline 7 & 0.594 & 0.479 & 19.302 & 4617 & 5772 & 600 & 80 \\
\hline 8 & 0.479 & 0.387 & 19.302 & 3718 & 4647 & 600 & 80 \\
\hline
\end{tabular}

Table no2 Typical Pass schedule

In 1st pass material fed to mill from uncoiler and coiled on tension reel on the exit side. Due to limitationofUncoiler unit there is a limitation on back tension. Actual rolling process starts from $2^{\text {nd }}$ pass hence our experiment conducted in $2^{\text {nd }}$ pass. In second pass strip fed from exit tension reel to Mill and coiled on tension reel on entry side. In accordance with the steps that are involved in Taguchi's Method, a series of experiments are to be conducted. Here, cold rolling of low carbon steel carried out in 4HI single stand cold rolling Mill at JSW Steel coated Product, Kalmeshwar Nagpur,India as a case study. The procedure is given below.

\section{Design of experiment Approach:}

Experimental design is a statistical technique that enables an investigator to conduct realistic experiments, analyze data efficiently, and draw meaningful conclusions from the analysis. The aim of scientific research is usually to show the statistical significance of an effect that a particular factor (input parameter) exerts on the dependent variable (output/response) of interest. Specifically, the goal of DOE is to identify the optimum values for the different control factors that affect the production process.The primary reason for using statistically designedExperiments is to obtain maximum information from minimum amount of resources being employed.

\section{III .1 Identify the main function and its side effects.}

Before proceeding on to further steps, it is necessary to list down all the factors that are going to affect or influence the thickness variation and flatness in rolling process and from those factors one has to identify the control and noise factors. The "Factors" that affect rolling operation on a cold rolling mill are listed below.

\section{Control factors Noise Factors}

Entry tension Input strip thickness variation.

Exit Tension Input strip hardness variation.

Rolling Speed Mill chattering.

Bending Pressure Input strip flatness. 


\section{Reduction Roll force \\ Coefficient of Coolant concentration}

Friction

After listing the control and the noise factors, decisions on the factors that significantly affect the performance will have to be ascertained and only those factors must be taken in to consideration in constructing the matrix for experimentation. All other factors are considered as Noise Factors in designing of experiment for Optimization of rolling parameter is consideredin second pass. There are various control input factors in a pass such as reduction, entry tension, exit tension, coefficient of friction, strip width, material to be rolled. Since we had carried out experiment keeping material input / output data, coefficient of friction and reduction unchanged. The control factors are entry tension (Backward), exit tension (forward) rolling speed \& roll bending pressure. The noise factors are input strip thickness variation, material hardness variation,coefficient of friction and strip flatness. The levels of control factors are decided, then accordingly to this array can be produced.

\section{III.2 Identifying the Testing Conditions and Quality Characteristics tobe observed.}

Quality Characteristic: One of the quality characteristics of rolled strip is Thickness variation, \% of total rolled strip length under specified acceptable limit $( \pm 0.05)$ of the target thickness. Target thickness in our experiment is $1.400 \mathrm{~mm}$ and allowable variation limit is $1.350 \& 1.450 \mathrm{~mm}$. Another quality characteristics of the rolled strip is flatness. Flatness for the strip measured in I value. The I-unit is a powerful description of the fiber length distribution in the strip width direction.

Material: Low carbon steel Grade ST29DC

Rolling Mill: Single stand cold rolling reversing Mill

Testing Equipment: There are two X- Ray Gauge at Entry and exit of Mill stand. The x ray gauge before entering mill bite measures input gauge and Gauge after mill measures output Gauge.After completion of the pass strip measurement and flatness analysis report generated, which shows graphical representation of thickness about target thickness and result of the analysis like standard deviation, average thickness and \% of the total rolled length of the strip rolled within acceptable limit.Flatness is measured by tension meter roll installed in either side of the mill. After completion of the pass strip flatness analysis report generated, which shows graphical representation of flatness and average of I value is reported at the end of the pass for the total length rolled in the pass.

\subsection{Identify the Objective Function}

The main objective of the cold rolling operation is to maximize $\%$ of the total length of rolled strip within acceptable tolerance limit is the better performance and minimize the I value for flatness improvement. Therefore the larger the better length of strip under permissibletolerance limitand flatness lesser than specified limit is selected for obtaining optimum rolling performance characteristics.

Objective Function for thickness variation: Larger -the-Better

The following $\mathrm{S} / \mathrm{N}$ ratios for the larger the better case could be calculated

$$
S / \text { NRatio }=-10 \log \left(\sum\left(\frac{1}{y^{2}}\right) / n\right)
$$

Where $\mathrm{n}=$ sample size and $\mathrm{y}=\%$ of the total rolled strip thickness under tolerance limit.

Where $\%$ of the total rolled strip thickness $=$ length of strip under tolerance limit X 100

Under tolerance limit total length of the rolled strip

More the length of the strip under tolerance limit better the performance.

Objective function for flatness: smaller the better

$$
\text { S/N Ratio }=\eta \quad \eta=-10 \log _{10}\left(\frac{1}{n} \sum_{i=1}^{n} y_{i}^{2}\right)
$$

Where $\mathrm{n}=$ sample size and $\mathrm{y}=\mathrm{I}$ value for rolled strip flatness.

Flatness for the strip measured in I value,The I-unit is a powerful description of the fiber length distribution in the strip width direction.

\section{III.4Identifying the Control Factors and their levels}

The factors and their levels were decided for conducting the experiment, based on a "brain storming session" that was held with a group of people and also considering the guide lines given in the operator's manual provided by the manufacturer of the rolling mill. The factors and their levels are shown in table $3 \& 4$.

\begin{tabular}{|l|c|}
\hline Factors Input variable & Levels \\
\hline Entry tension & 3 \\
\hline Exit tension & 3 \\
\hline Rolling speed & 3 \\
\hline
\end{tabular}




\begin{tabular}{|l|l|}
\hline Bending pressure & 3 \\
\hline
\end{tabular}

Table 3 shows the factors and levels for each input factors

\begin{tabular}{|l|l|c|c|c|}
\hline Factor & \multirow{2}{*}{ Units } & \multicolumn{3}{|c|}{ Levels } \\
\cline { 3 - 5 } & & 1 & 2 & 3 \\
\hline Exit tension & $\mathrm{Kgs}$ & 11000 & 11600 & 12200 \\
\hline Entry tension & $\mathrm{Kgs}$ & 6000 & 6600 & 7200 \\
\hline Mill Speed & $\mathrm{mpm}$ & 400 & 500 & 600 \\
\hline Bending Pressure & $\mathrm{Kg} / \mathrm{cm} 2$ & 70 & 80 & 90 \\
\hline
\end{tabular}

Table No.4 Factors and there Levels in Design of experiment

\section{III.5 Conductingthe Matrix Experiment}

There are four control factors with 3 levels in our experiment. The most suitable orthogonal for experimentation for this project is L9 available in standard orthogonal array.The experimental layout with the selected values of the factors is shown in Table 5. Each of the 9 experiments were conducted to account for the variations that may occur due to the noise factors. The thickness at the exit was measured using $\mathrm{x}$ ray gauge and thickness variation reports recorded from reports generated after finishing one complete pass. The table 5 shows the experimental design and results of nine experiments.

\begin{tabular}{|c|c|c|c|c|c|c|c|c|c|}
\hline \multirow[t]{2}{*}{$\begin{array}{c}\text { Experiment } \\
\text { No. }\end{array}$} & $\begin{array}{l}\text { Entry } \\
\text { thk }\end{array}$ & $\begin{array}{l}\text { Exit } \\
\text { thk }\end{array}$ & Reduction & $\begin{array}{l}\text { Exit } \\
\text { tension }\end{array}$ & $\begin{array}{l}\text { Entry } \\
\text { tension }\end{array}$ & $\begin{array}{c}\text { Mill } \\
\text { Speed }\end{array}$ & $\begin{array}{l}\text { Bending } \\
\text { Pressure }\end{array}$ & $\begin{array}{l}\text { total Length of } \\
\text { strip within limit }\end{array}$ & $\begin{array}{c}\text { Avg. } \\
\text { Flatness }\end{array}$ \\
\hline & $\mathrm{mm}$ & $\mathrm{mm}$ & $\%$ & $\mathrm{Kg}$ & $\mathrm{Kg}$ & $\mathrm{mpm}$ & $\mathrm{Kg} / \mathrm{cm} 2$ & $\%$ & I Value \\
\hline 1 & 1.75 & 1.4 & 19.302 & 11000 & 6000 & 400 & 70 & 71 & 35.1 \\
\hline 2 & 1.75 & 1.4 & 19.302 & 11000 & 6600 & 500 & 80 & 65 & 41.2 \\
\hline 3 & 1.75 & 1.4 & 19.302 & 11000 & 7200 & 600 & 90 & 74 & 52.8 \\
\hline 4 & 1.75 & 1.4 & 19.302 & 11600 & 6000 & 400 & 90 & 75 & 41.3 \\
\hline 5 & 1.75 & 1.4 & 19.302 & 11600 & 6600 & 500 & 70 & 72 & 37.5 \\
\hline 6 & 1.75 & 1.4 & 19.302 & 11600 & 7200 & 600 & 80 & 69 & 44.8 \\
\hline 7 & 1.75 & 1.4 & 19.302 & 12200 & 6000 & 400 & 80 & 78 & 39.3 \\
\hline 8 & 1.75 & 1.4 & 19.302 & 12200 & 6600 & 500 & 90 & 70 & 50.4 \\
\hline 9 & 1.75 & 1.4 & 19.302 & 12200 & 7200 & 600 & 70 & 67 & 42.6 \\
\hline
\end{tabular}

Table 5 Orthogonal array with the response thickness variation and flatness

III.6Analysis of single response:

The following are the experimental results of the work carried out.

Experimental Details

Analysis of individual response carried out, for thickness variation the objective function (\% of the total length under specified thicknessacceptable limit)is larger -the-better type of control function was used in calculating the $\mathrm{S} / \mathrm{N}$ ratio. For flatness improvement minimize the I value smaller the better control function was used.The $\mathrm{S} / \mathrm{N}$ ratios of all the experiments were calculated and tabulated for both the response as shown in Table 6.

\begin{tabular}{|c|c|c|}
\hline $\begin{array}{c}\text { Experiment } \\
\text { No. }\end{array}$ & $\begin{array}{c}\text { S/N Ratio } \\
(\mathbf{d b}) \text { Thk }\end{array}$ & $\begin{array}{c}\text { S/N Ratio } \\
(\mathbf{d b}) \text { Flatness }\end{array}$ \\
\hline 1 & 37.025 & -30.9 \\
\hline 2 & 36.258 & -32.29 \\
\hline 3 & 37.384 & -34.45 \\
\hline 4 & 37.501 & -32.33 \\
\hline 5 & 37.146 & -31.4 \\
\hline 6 & 35.375 & -33.02 \\
\hline 7 & 37.842 & -31.88 \\
\hline 8 & 36.901 & -34.04 \\
\hline 9 & 36.521 & -32.58 \\
\hline
\end{tabular}

\begin{tabular}{|c|c|c|c|c|c|c|c|c|}
\hline \multirow{2}{*}{ Level } & \multicolumn{2}{|c|}{ Entry tension } & \multicolumn{2}{c|}{ Exit Tension } & \multicolumn{2}{c|}{ Rolling speed } & \multicolumn{2}{c|}{ Roll bending pressure } \\
\cline { 2 - 7 } & $\begin{array}{c}\text { Avg S/N } \\
\text { ratio (Thv) }\end{array}$ & $\begin{array}{c}\text { Avg S/N } \\
\text { ratio (Flv) }\end{array}$ & $\begin{array}{c}\text { Avg S/N } \\
\text { ratio (Thv) }\end{array}$ & $\begin{array}{c}\text { Avg S/N } \\
\text { ratio (Flv) }\end{array}$ & $\begin{array}{c}\text { Avg S/N } \\
\text { ratio (Thv }\end{array}$ & $\begin{array}{c}\text { Avg S/N } \\
\text { ratio (Flv) }\end{array}$ & $\begin{array}{c}\text { Avg S/N } \\
\text { ratio (Thv }\end{array}$ & $\begin{array}{c}\text { Avg S/N } \\
\text { ratio (Flv) }\end{array}$ \\
\hline
\end{tabular}

Table 6 Tabulated S/N ratios 
Taguchi approach with multiple performance characteristics for improving productivity and quality

\begin{tabular}{|l|l|l|l|l|l|l|l|l|}
\hline 1 & 36.889 & -32.457 & 37.456 & -31.703 & 36.434 & -32.653 & 36.897 & -31.657 \\
\hline 2 & 36.674 & -32.250 & 36.768 & -32.577 & 36.760 & -32.400 & 36.492 & -32.397 \\
\hline 3 & 37.088 & -32.833 & 36.427 & -33.350 & 37.457 & -32.577 & 37.262 & -33.607 \\
\hline
\end{tabular}

The average of the signal to noise ratios is shown in table 7. Similarly S/N ratios can be calculated for other factors.

Table 7: Average S/N Ratios for each response

The optimal settings and the predicted optimal values for thickness variation and flatness variation are determined individually by taguchi approach. ANOVA is used to determine the optimum combination of process parameters more accurately by investigation relative process parameters. Table 8 parameters with optimum level for thickness variation and flatness.

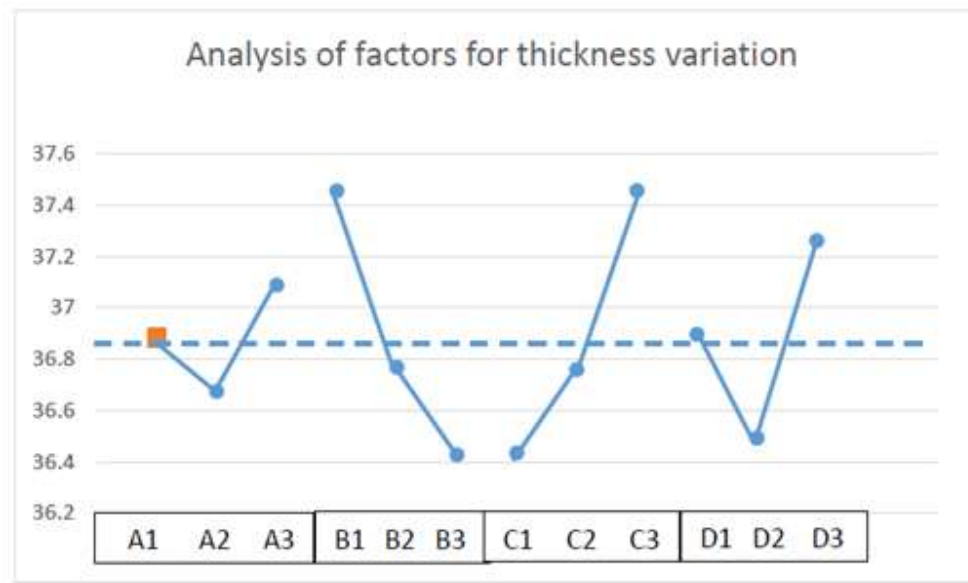

Fig 2 Charts showing factor level vs thickness variation response S/N Ratio

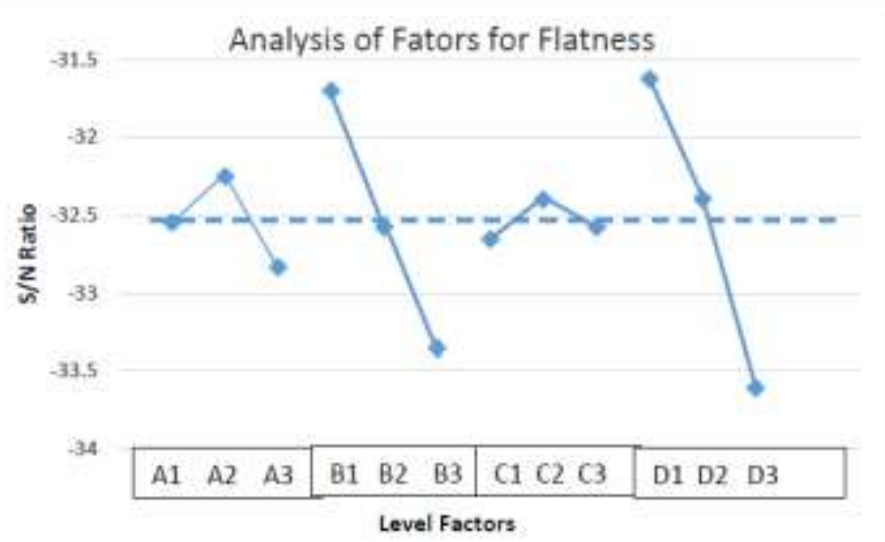

Fig 3Charts showing factor level vs Flatness response S/N Ratio

\begin{tabular}{|c|c|c|c|c|}
\hline Process Parameters & $\begin{array}{c}\text { Optimum level for } \\
\text { thk variation }\end{array}$ & $\begin{array}{c}\text { Optimum values } \\
\text { for thk variation }\end{array}$ & $\begin{array}{c}\text { Optimum level for } \\
\text { flatness variation }\end{array}$ & $\begin{array}{c}\text { Optimum values for } \\
\text { flatness variation }\end{array}$ \\
\hline Exit Tension & A3 & 12000 & A2 & 11600 \\
\hline Entry Tension & B1 & 6000 & B1 & 6000 \\
\hline Rolling Speed & C3 & 600 & C2 & 500 \\
\hline Bending Pressure & D3 & 80 & D1 & 60 \\
\hline
\end{tabular}

Table 8 Factors with optimum levels for thickness variation and Flatness.

\begin{tabular}{|c|c|c|c|}
\hline Factor / Source & Degree of freedom & Sum of square & \% Sum of square \\
\hline Exit Tension & 2 & 0.2572 & 5.79 \\
\hline Entry Tension & 2 & 1.649 & 37.15 \\
\hline Rolling Speed & 2 & 1.640 & 36.96 \\
\hline Bending Pressure & 2 & 0.891 & 20.07 \\
\hline Noise e & & 0.00 & 0.0 \\
\hline Total & 8 & 4.438 & \\
\hline
\end{tabular}

Table 9 ANOVA results for Thickness variation

\begin{tabular}{|c|c|c|c|}
\hline Factor / Source & Degree of freedom & Sum of square & $\%$ Sum of square \\
\hline Exit Tension & 2 & 0.5105 & 4.787 \\
\hline
\end{tabular}




\begin{tabular}{|c|c|c|c|}
\hline Entry Tension & 2 & 4.0723 & 38.19 \\
\hline Rolling Speed & 2 & 0.1013 & 0.94 \\
\hline Bending Pressure & 2 & 5.9774 & 56.06 \\
\hline Noise e & & 0.3337 & 3.12 \\
\hline Total & 8 & 10.6614 & \\
\hline
\end{tabular}

Table 10 ANOVA results for flatness

ANOVA is used to find the optimum combination of process parameters more accurately by investigating the relative importance of process parameters. Table $9 \& 10$ shows the results of ANOVA for thickness variation and flatness respectively. It is observed that the entry tension $(37.15 \%)$ and rolling speed (36.96\%) are most significantly influence thickness variation followed by bending pressure (20.07\%). In case of Flatness improvement entry tension $(38.19 \%)$ and bending pressure $(56.06 \%)$ are most significant parameters followed by exit tension $(4.78 \%)$. In both case the error contribution negligible $(0 \% \& 3.12 \%)$ reveals that the interaction effect of the process parameters is negligible. The optimum parameters levels can be obtained from the mean value table 7. In case of thickness variation the objective is to maximize the response, maximize the

\begin{tabular}{|l|l|l|l|l|l|l|l|l|}
\hline \multirow{2}{*}{ Level } & \multicolumn{2}{|l|}{ Entry tension } & \multicolumn{2}{l|}{ Exit Tension } & \multicolumn{2}{l|}{ Rolling speed } & \multicolumn{2}{l|}{ Roll bending pressure } \\
\cline { 2 - 9 } & $\begin{array}{l}\text { Sum } \\
\text { Sentj) }\end{array}$ & $\begin{array}{l}\text { Avg S/N } \\
\text { ratio }\end{array}$ & Sum (Sentj) & $\begin{array}{l}\text { Avg S/N } \\
\text { ratio }\end{array}$ & Sum (Sentj) & $\begin{array}{l}\text { Avg S/N } \\
\text { ratio }\end{array}$ & Sum (Sentj) & $\begin{array}{l}\text { Avg } \\
\text { ratio }\end{array}$ \\
\hline 1 & 6.514 & 2.171 & 8.629 & 2.876 & 5.671 & 1.890 & 7.906 & 2.635 \\
\hline 2 & 6.636 & 2.212 & 6.288 & 2.096 & 6.540 & 2.180 & 6.143 & 2.048 \\
\hline 3 & 6.382 & 2.127 & 4.615 & 1.538 & 7.321 & 2.440 & 5.483 & 1.828 \\
\hline
\end{tabular}

S/N Ratio. Hence optimum values factor levels are A3-B1-C3-D3. In the case of flatness improvement the objective is to minimize the response, maximize the S/N Ratio. Hence the optimum values of factor levels are A2-B1-C2-D1.

\section{Analysis of Multi- response:}

The main objective of the cold rolling operation is to maximize $\%$ of the total length of rolled strip within

Table 11: Average S/N Ratios for each factor

Acceptable tolerance limit is the better performance and minimize theI value for flatness improvement. In the present work, a multi-response methodology based on Taguchi technique and Utility concept is used for optimizing the multi-responses (Thickness variation \& Flatness). Taguchi proposed many different possible S/N ratio to obtain the optimum parameters setting. Those two of them are selected for the present work. Those are, larger the better $\mathrm{S} / \mathrm{N}$ ratio for thickness variation, smaller the better type $\mathrm{S} / \mathrm{N}$ ratio for flatness. From Utility concept the multi-response $\mathrm{S} / \mathrm{N}$ ratio of the overall utility values is given by nobs $=\mathrm{W} 1 * \mathrm{n} 1+\mathrm{W} 2 * \mathrm{n} 2$ where $\mathrm{W} 1$ \& W2 are the weights assigned to the thickness variation and flatness. Assignment of weights to the performance characteristics are based on experience of mill operation, customer's requirements and their priorities. In the present work equal importance is given for both thickness variation and flatness improvement, hence W1 \& W2 $=0.5$.Average $\mathrm{S} / \mathrm{N}$ Ratio for all the factors level were determined,table No 11 shows the average S/N Ratio for each factor at all levels. The factor effect for multi response corresponding to the highest $\mathrm{S} / \mathrm{N}$ ratio were chosen to optimize the condition. The charts fig $4 \& 5$ shows the variations of multi response with four rolling parameters i.e. entry tension, exit tension, rolling speed and roll bending pressure.
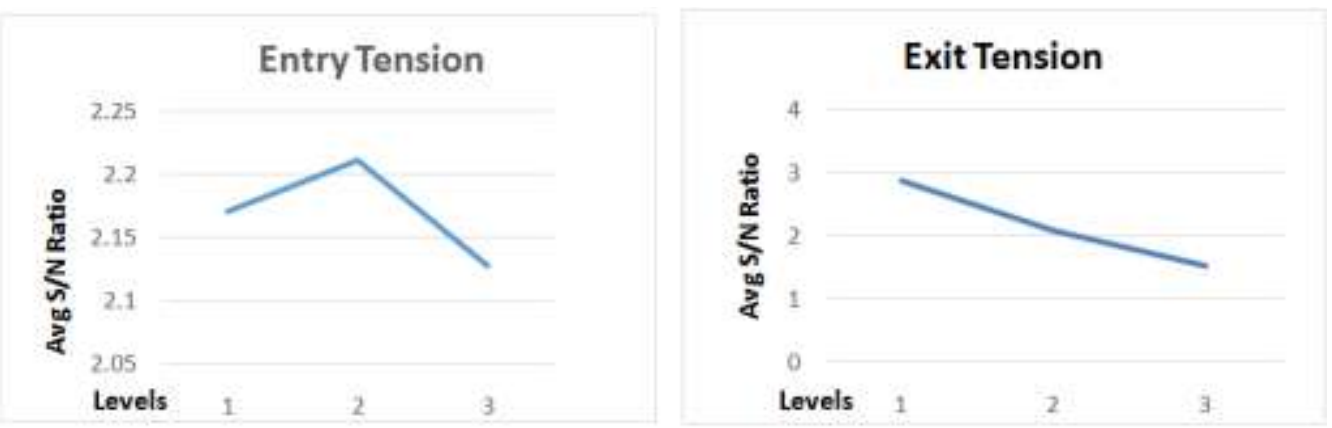

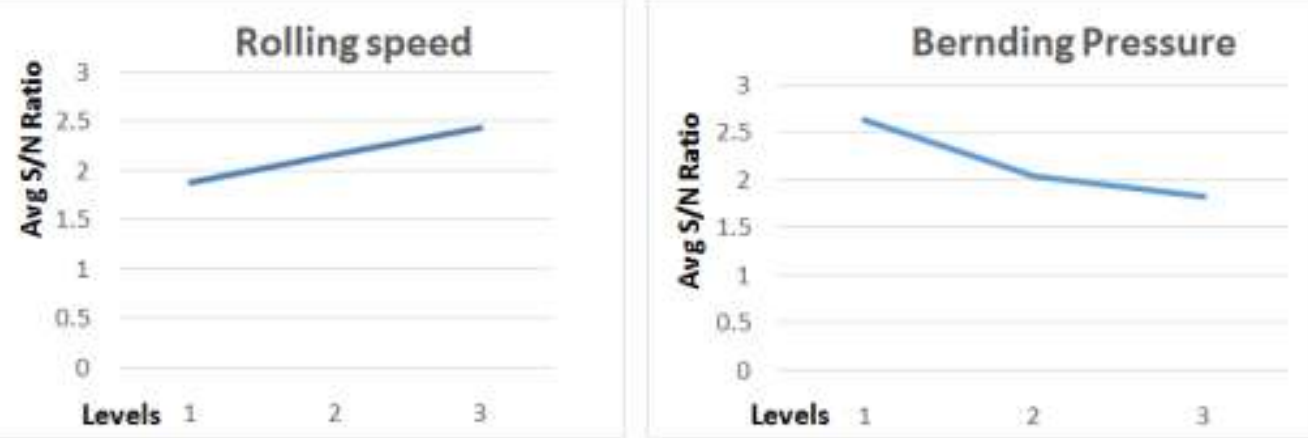

Fig4Charts showing factor level vs Multi response S/N Ratio

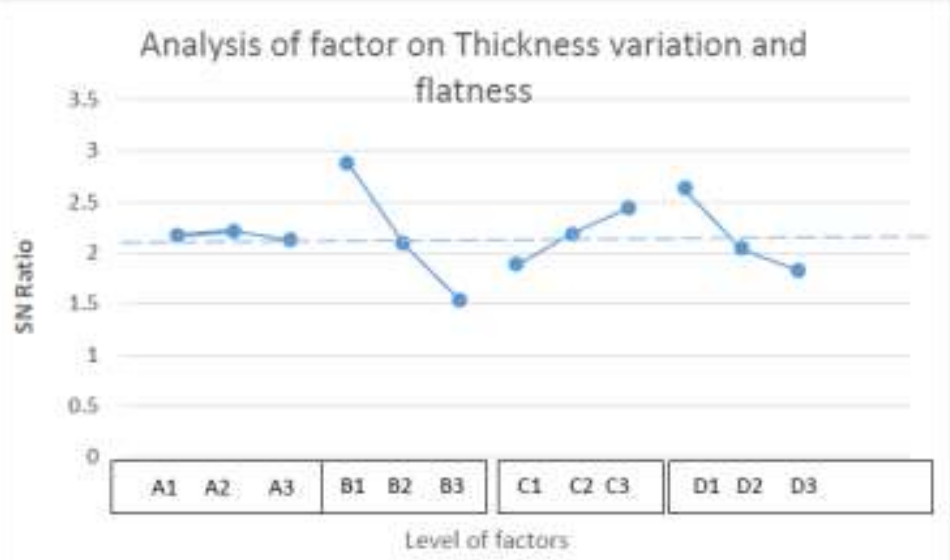

Fig $\mathbf{5 C h a r t s ~ s h o w i n g ~ f a c t o r ~ l e v e l ~ v s ~ M u l t i ~ r e s p o n s e ~ S / N ~ R a t i o ~}$

Interpretation of Plots chart 5 shows main effect plot for multi response, it is observed that optimum values for process parameters are

Exit Tension $(\mathrm{Kg}) \quad 11600$

Entry Tension $(\mathrm{Kg}) \quad 6000$

Rolling Mill Speed (mpm)600

Roll Bending Pressure (Bar) 70

\subsection{ANOVA of Multiple factors:}

According to Table No. 12 for the results of ANOVA multiple response performance characteristics, Exit tension $(51.97 \%)$ is the most significant parameter affecting the performance followed by roll bending pressure $(20.06 \%)$. The percent contribution of the rolling speed $(8.71 \%)$ is much lower and exit tension $(0.2 \%)$ is much much lower. The error contribution(19.036\%) reveals that the interaction effect of the process parameters is significant.

\begin{tabular}{|l|l|l|l|}
\hline Parameter & DOF & SS & SS $\%$ \\
\hline Entry Tension & 2 & 0.0108 & 0.206 \\
\hline Exit tension & 2 & 2.7102 & 51.97 \\
\hline Rolling speed & 2 & 0.4545 & 8.71 \\
\hline Bending Pressure & 2 & 1.0452 & 20.06 \\
\hline Noise, e & & 0.9926 & 19.036 \\
\hline Total & 8 & 5.2143 & \\
\hline
\end{tabular}

Table 12 ANOVA results for multi response

\section{Conclusion}

The present work is deal with finding out ways to determine the optimum setting of process parameters for multi response optimization of process parameters of cold rolling process. Multi characteristics response optimization model based on Taguchi and utility concept is used to optimize process parameters entry tension, exit tension, rolling speed \& roll bending pressure on multiple performance characteristics such as strip thickness variation and strip flatness. According to Taguchi approach a special design of orthogonal arrays L9 has been selected, only nine experiments were needed to determine the optimum condition for the cold rolling process.The experiment results showed that combination of process parameters is essential to achieve simultaneous maximum length under permissible thickness variation and minimization of I value flatness 
improvement. Based on the ANOVA the most statistical significant and percent contribution of each control process parameters for multiple performance is analyzed. It is concluded that the proposed model based on Taguchi approach and Utility concept is simple, useful and provides an appropriate solution for multi-response optimization.

Scope of work:The above experiment carried out in $2^{\text {nd }}$ pass and optimum values for control factors were obtained for multiple response like thickness variation and strip flatness. Similar concept can be used for optimizing control factor for response like low power consumption and higher production rate. Similar experiment can also be carried out in remaining 6 pass by carrying out 9 experiment for each pass and their optimum values for the respective pass can be obtained. Finally pass schedule based on optimum values of all eight pass can be made and final experimentation can be carry out to obtained best performance in strip output for multiple response thickness variation, improved flatness, power consumption and production rate.

\section{References}

[1]. Roberts, W., Cold Rolling of Steel, Marcel Dekker, 1978, Chpt. 9

[2]. Vaidya V.A." Optimization of cold rolling mill process to improve productivity and Product Quality of steel - an overview "2015 IJEDR | Volume 3, Issue 4 | ISSN: 2321-9939 V

[3]. Vaidya V.A."Application of Taguchi for Optimization of Process Parameters inimproving Thickness Variation in Single Stand Cold Rolling Mill”.IRJESISSN (Online) 2319-183X, (Print) 2319-1821 Volume 5, Issue 5 (May 2016), PP.15-23

[4]. Malhotra, N. "Optimization of multiple quality characteristicsof EDM process for MRR and TWR using utility concept". Advances in Production Engineering \& Management ISSN 1854-6250Volume 8 | Number 4 | December 2013 | pp 219-230.

[5]. KishanChoudhuri."Optimization of multi-objective problem by taguchiApproach and utility concept when turningAluminum 6061. Proceedings of Fifth IRF International Conference, 10th August 2014, Goa, India, ISBN: 978-93-84209-45-2.

[6]. N. Gaitonde, Karnik, Paulo Davim, "Multi-performanceOptimization in turning of Free-machining Steel Using Taguchi Method and Utility concept". Journal of MaterialsEngineering and Performance,18 (3), 231 (2009).

[7]. Bland, D. R. and Ford, H., "The calculation o roll force and torque in cold strip rolling with tensions," Proc. Inst. Mech. Eng., 1948, Vol. 159, pp. 144-153.

[8]. Taguchi G, Konishi S ,Taguchi Methods, orthogonal arrays and linear graphs, tools for quality American supplier institute, American Supplier Institute; 1987 [p. 8-35]

[9]. W.T. Foster, Basic Taguchi design of experiments, National Association of Industrial Technology Conference, Pittsburgh, PA, 2000

[10]. P. J. Ross, "Taguchi Techniques for Quality Engineering”,McGraw-Hill Book Company, NewYork, (1996).

[11]. Ali Heidari , Mohammad R. Forouzan Optimization of cold rolling process parameters in order to increasing rolling speed limited by chatter vibrations Journal of Advanced Research (2013) 4, 27-34.

[12]. Bendell, Disney \&Pridmore, Taguchi Methods-Application in world industry, IFS 1989.

[13]. Madhav S Phadke, "Quality Engineering Using Robust Design".

[14]. Wang, D. D., Tieu, A. K., DeBoer, F. G., Ma, B. \& Yuen, W. Y. D. (2000). Toward a heuristic optimum design of rolling schedules for tandem cold rolling mills. Engineering Applications of Artificial Intelligence, 13 (4), 397-406. 